\title{
Desenvolvimento de coleções em bibliotecas universitárias: uma abordagem quantitativa
}

\section{Ana Maria Mattos}

\begin{abstract}
Bibliotecária da Escola de Administração da Universidade Federal do Rio Grande do Sul. Mestre em Ciência da Informação. Doutoranda do Programa de Pós-Graduação da Escola de Ciência da Informação da Universidade Federal de Minas Gerais
\end{abstract}

Eduardo José Wense Dias

\begin{abstract}
Professor aposentado da Escola de Ciência da Informação da Universidade Federal de Minas Gerais
\end{abstract}

A análise das citações utilizadas na elaboração de teses acadêmicas pode servir de apoio à tomada de decisão no desenvolvimento de coleções da biblioteca universitária. Examinar a tipologia, idade da literatura, idioma e títulos de periódicos citados possibilita melhorar a distribuição do orçamento, traçar diretrizes para armazenamento, determinar a coleção-núcleo de periódicos e avaliar em quais idiomas devem ser selecionados os materiais bibliográficos em futuras aquisições.

Palavras-chave:

Biblioteca

universitária; Desenvolvimento de Coleções; Análise de Citações.

\section{Collections development in academic libraries: a quantitative approach}

Citation analysis of the bibliography used in the elaboration of academic dissertations can support the decision-making process in collection development in the university library. The analysis of the type of materials, its obsolescence, its languages, and the titles of journals cited will make it possible to improve the distribution of the budget; to establish guidelines for storage; to determine the composition of the core collection of journals; and to identify languages in which the bibliographical materials should be acquired. 
Keywords: University Library; Collection Development; Citation Analysis.

Recebido em 01.02.2008 Aceito em 04.12.2009

\section{Introdução}

Tradicionalmente, bibliotecas universitárias têm a missão de prover a infra-estrutura bibliográfica, documentária e informacional para apoiar todas as atividades inerentes à universidade (RUSSO, 2007). Este tipo de biblioteca surgiu na Idade Média ligada às ordens religiosas, que deram sustentação ao movimento de criação das universidades. Naquela época, os livros eram manuscritos, o que dificultava e encarecia sua reprodução, mas, apesar disso, as universidades sempre dispuseram de bibliotecas, mesmo que de forma rudimentar (CARVALHO, 2004; VERGER, 1999).

Com o passar do tempo, o número de estudantes universitários começou a aumentar, ocasionando um crescimento da produção intelectual, coincidindo com a decadência da Idade Média, o surgimento do Renascimento e a difusão, na Europa, da tecnologia de reprodução por tipos móveis. Comparadas aos padrões atuais, as coleções existentes nas bibliotecas, antes do advento da imprensa no Ocidente, caracterizavam-se por serem de pequeno porte. As mudanças atingiram a biblioteca universitária: "quanto mais se lia, mais se produzia conhecimento o que aumentava o campo para novos estudos. Este ciclo cresceu aumentando a relação entre a universidade, a biblioteca e os seus leitores" (MORIGI; SOUTO, 2005, p. 191).

Cabe à biblioteca universitária satisfazer as demandas informacionais de seus usuários para que eles desempenhem adequadamente suas atividades de ensino, pesquisa e extensão. Uma das funções que mais necessita de atenção na administração de uma biblioteca é o desenvolvimento de coleções, processo conhecido durante muito tempo apenas como seleção. Desde então, tem sido destacada na literatura como uma das mais importantes atividades intelectuais do bibliotecário, muito embora a mesma literatura reporte a dificuldade de tornar a teoria em prática sistemática.

As coleções, que eram formadas de maneira elementar exigem, na atualidade, uma gestão criteriosa e atenta em seu processo de desenvolvimento, de modo que seja possível determinar diretrizes para nortear sua implementação. Para se atingir o objetivo último do desenvolvimento de coleções - a satisfação dos usuários - é importante coletar e organizar os dados referentes ao comportamento dos mesmos, visando apoiar a tomada de decisão.

Smith (1981) sugere que a análise das citações oriundas das teses e dissertações pode servir como um estudo do usuário, pois elas oferecem dados que podem gerar informações valiosas quanto àquele comportamento. 
Considerando-se pertinente o proposto por Smith (1981), investigase o comportamento de uso dos materiais informacionais dos alunos de doutorado do Programa de Pós-Graduação em Administração (PPGA) da Escola de Administração (EA) da Universidade Federal do Rio Grande do Sul (UFRGS), pela análise das citações expressas nas teses por eles elaboradas, objetivando-se estabelecer diretrizes para apoiar a tomada de decisão quanto ao desenvolvimento de coleções da Biblioteca Setorial da EA (BSEA).

Intenciona-se, ainda, encontrar respostas para duas indagações identificadas como problemas de pesquisa: (a) seriam as referências citadas nas teses de Administração um indicador representativo que possa servir de base para a elaboração de uma política de desenvolvimento de coleções na área? (b) como o usuário, aluno de doutorado em Administração, se comporta no uso dos materiais informacionais?

O foco desta investigação encontra-se no comportamento de uso do material informacional dos alunos de pós-graduação, pois os alunos de graduação da UFRGS já se encontram contemplados com uma política de desenvolvimento de coleções, que vem sendo desenvolvida pelo Sistema de Bibliotecas da UFRGS por meio da metodologia BiblioGrad (STREHL; CASTANHO, 2007). Além disso, optou-se pelo estudo das citações utilizadas na elaboração das teses porque elas representam estudos originais, constituem-se em uma contribuição real para a especialidade e o material informacional utilizado na sua elaboração apresenta o que há de mais atual sobre o assunto abordado.

Objetiva-se identificar: (a) a tipologia dos materiais bibliográficos empregados nas citações, visando a melhorar a distribuição dos recursos financeiros disponíveis para investimento em inclusão, substituição e prioridades na coleção geral da biblioteca; (b) a idade da literatura dos materiais informacionais citados, pretendendo 0 armazenamento retrospectivo da coleção; (c) os títulos de periódicos citados, determinando a coleção-núcleo e preparando possíveis cortes na coleção devido a, por exemplo, eventuais reduções no orçamento da biblioteca; e (d) a preferência dos idiomas dos materiais consultados, distinguindo os que devem ocorrer nos materiais bibliográficos selecionados em futuras aquisições.

\section{Desenvolvimento de coleções}

Pode-se afirmar que a Biblioteca de Alexandria, na Antiguidade, representava o resultado da seleção de algumas obras que eram "[...] símbolo da liberdade de expressão e de compromisso com a memória social daquele período". Da mesma forma, na Idade Média, a seleção das obras colecionadas representava o resultado de uma lógica cristã. Dos "tabletes de argila ao documento eletrônico não há como formar e desenvolver coleções sem se deparar com questões próprias da natureza do processo, tais como o que se vai colecionar, por que, para quê e para quem colecionar" (WEITZEL, 2002, p. 61). No Renascimento, o processo de seleção foi tratado de modo mais sistemático pelo médico francês 
Gabriel Naudé (1600-1653), em sua obra Avis pour dresser une bibliothèque e, na Idade Moderna, colecionava-se praticamente tudo o que existia, pois a produção editorial encontrava-se em seu estágio inicial.

Contudo, foi na segunda metade do século $X X$, que 0 desenvolvimento de coleções tornou-se importante devido à irracionalidade de se adquirir todo o material informacional que era produzido. Este vinha adquirindo proporções gigantescas, devido ao fenômeno conhecido como explosão informacional (FONSECA, 2007; WEITZEL, 2002). O processo inicia-se, mais precisamente, nas bibliotecas universitárias de países anglo-saxões, em grande medida, em virtude das restrições orçamentárias. Entretanto, mesmo que não houvesse tais restrições, o crescimento exponencial das coleções e a carência de espaço físico obrigavam os bibliotecários a implementarem políticas mais precisas de descarte e armazenamento. Ou seja, a atividade de desenvolvimento de coleções surge como resposta à explosão bibliográfica.

Vergueiro (1989, p. 15) assevera que o "desenvolvimento de coleções é, acima de tudo, um trabalho de planejamento [...] trata-se de um processo que ao mesmo tempo, afeta e é afetado por muitos fatores externos a ele". Como exemplo, há as novas tecnologias de informação e comunicação e a integração crescente das fontes eletrônicas aos acervos e serviços existentes nas bibliotecas, que, de acordo com Cunha (2000), até 2010 provocariam grandes transformações nos serviços de desenvolvimento de coleções e aquisição.

Menos inquietante, Vergueiro (1997, p. 101) nos apresenta uma perspectiva de muitas e não de grandes transformações: "Num mundo onde materiais impressos conviverão - espera-se que em harmonia - com todas as demais fontes eletronicamente disponíveis, serão muitas as implicações para as atividades daqueles profissionais responsáveis pelo desenvolvimento das coleções".

Contudo, apesar da previsão de grandes transformações nos serviços de desenvolvimento de coleções feita por Cunha (2000) e de muitas transformações previstas por Vergueiro (1997), "[...] os princípios para desenvolvimento de coleções que regem os documentos impressos são os mesmos que regem os objetos digitais" (WEITZEL, 2006, p. 8); ou como conclui Vergueiro (1997, p. 104), "as preocupações dos profissionais de informação, no que diz respeito ao desenvolvimento de coleções, manterão grande nível de similaridade com as que possuem no ambiente da informação predominantemente impressa".

Da mesma maneira que as restrições orçamentárias, a explosão informacional e a carência de espaço físico promoveram a disciplina de desenvolvimento de coleções no século passado, as novas mídias e as tecnologias de informação e comunicação tornam o desenvolvimento de coleções o centro das atenções na atualidade.

A questão da acumulação versus a seleção orientada para a qualidade, a relevância e o acesso à informação renascem, e, "do ponto de vista teórico, os dois grandes momentos apresentados são fundamentais e se complementam para explicar a importância do processo de desenvolvimento de coleções para a organização do 
conhecimento" (WEITZEL, 2006, p. 66). Ou ainda, de acordo com Vergueiro (1997, p. 104), "talvez a importância social da atividade tenha até mesmo sido incrementada pelo advento das tecnologias de informação eletrônica, ao invés de ter sido minimizada".

\subsection{Desenvolvimento de coleções na biblioteca universitária}

A crescente complexidade das atividades de geração e comunicação da informação provocou uma especialização das bibliotecas e os novos desafios na organização dos estoques de informação distanciaram as unidades de informação entre si. Apesar disso, pontos em comum continuaram existindo, pois, independentemente dos usuários atendidos e das características ambientais, as funções de seleção, aquisição, tratamento, organização, armazenamento e atendimento de referência são encontradas nos mais diversos tipos de bibliotecas (DIAS, 2006).

Percebe-se que os diferentes tipos de bibliotecas sentem de forma desigual a pressão exercida tanto pela informação disponível eletronicamente, quanto pelas novas tecnologias de informação e comunicação. Segundo Vergueiro (1997), por suas peculiaridades, as bibliotecas de pesquisa sentiriam mais rapidamente e com mais intensidade as mudanças provocadas pela informação disponível em meio eletrônico do que as bibliotecas públicas. Por esta razão, de acordo com o tipo de biblioteca, uma ou outra etapa do desenvolvimento de coleções é enfatizada. No caso da biblioteca universitária, devido aos seus objetivos institucionais e tipo de clientela, a ênfase encontra-se na avaliação e no desbastamento da coleção (WEITZEL, 2006).

A preocupação com a política de desenvolvimento de coleções na biblioteca universitária brasileira surge entre o final da década de 70 e início de 80, do século passado. Na ocasião, Antonio Miranda enumerava os problemas enfrentados para formar coleções nestas bibliotecas, tais como censura e inflação; e Nice Figueiredo pesquisava, por solicitação da Capes, a situação da seleção e aquisição de material bibliográfico nas bibliotecas acadêmicas.

Naqueles tempos, não havia literatura em português sobre o assunto e o ensino da disciplina de Formação e Desenvolvimento de Coleções tinha sido recém-introduzido nas escolas de Biblioteconomia. Apesar de o contexto atual encontrar-se mais favorável, passou o tempo, e as bibliotecas universitárias brasileiras quase não modificaram suas atividades de desenvolvimento de coleções (WEITZEL, 2006). Dessa forma, os fenômenos "especialização das bibliotecas" e "explosão bibliográfica" remetem-nos aos questionamentos de Vergueiro (1993, p. 19): "Afinal, estão as coleções sendo realmente desenvolvidas com critérios neste país? Estão elas seguindo qualquer tipo de parâmetro para seu desenvolvimento?"

Cuidar da formação adequada da coleção é uma das tarefas mais importantes e significativas do trabalho do bibliotecário. Tarefa importante porque the permite antecipar-se às demandas informacionais da 
comunidade usuária, pelo planejamento, visando adequar-se aos ambientes/fatores/interlocutores em que a biblioteca está inserida, tais como: direção da unidade, política, legislação, mudanças sociais ou demográficas, mercado editorial, inovações tecnológicas e padrões de desempenho exigidos (DIAS; PIRES, 2003).

No ambiente das bibliotecas universitárias, o desenvolvimento de coleções requer a compreensão das demandas informacionais dos autores das teses. Estas demandas podem ser difíceis de discernir, mas a análise de citações das teses possibilitará a compreensão clara de sua natureza (WILLIAMS; FLETCHER, 2006).

As bibliotecas acadêmicas não podem perder de vista os interesses de informação de seus usuários. Neste campo de atuação, a utilização de critérios quantitativos no processo de desenvolvimento de coleções pode ajudar a estabelecer um acervo capaz de atender a estes interesses e demandas, colaborando no processo decisório.

\section{Tomada de decisão e desenvolvimento de coleções}

A tomada de decisão consiste basicamente na identificação do problema, na coleta e análise de informações sobre ele e na conversão dessas informações em ação (BUCHANAN, O'CONNELL, 2006). Há uma busca contínua por novas ferramentas e novos modos de pensar para ajudar neste processo e, sob esta perspectiva, métodos quantitativos são instrumentos que devem ser considerados.

Tarapanoff, Miranda e Araújo Júnior (2004, p. 127) definem a tomada de decisão como "[... um] conjunto de atitudes que buscam a resolução de um problema específico (planejamento, organização, controle, estatística, etc.)". Percebe-se assim que a tomada de decisão é muito mais do que o momento final da escolha, é um processo complexo de reflexão, investigação e análise (TARAPANOFF, 2001).

Neste sentido, destaca-se que, no processo de desenvolvimento de coleções, a interpretação das análises quantitativas das coleções é um instrumento auxiliar na tomada de decisão, que se relaciona com planejamento, seleção, revisão e desbastamento, sendo "[...] impraticável desenvolver uma coleção que reúna todos os itens publicados em qualquer área do conhecimento" (FIGUEIREDO; LIMA, 1998, p. 81, grifos dos autores).

Entre os métodos e as técnicas do processo decisório, Dias e Pires (2003, p. 27) incluem a Bibliometria "[...] que elabora indicadores de tendências, gráficos, figuras e mapas que sintetizarão as informações para a tomada de decisão". A Bibliometria investiga o uso dos documentos, buscando padrões quantitativos para análise $e$, tal pesquisa pode servir como ferramenta auxiliar do planejamento.

A Bibliometria oferece, a partir do estabelecimento de padrões quantitativos, modelos de comportamento, não só do conhecimento ou da literatura, mas também das necessidades informacionais centradas no usuário, acumulando dados que, devidamente agrupados, auxiliam o 
processo de tomada de decisão (TARAPANOFF; MIRANDA; ARAÚJO JÚNIOR, 2004, p. 97).

Visando monitorar o ambiente, a coleta e a análise de informações sobre um determinado problema, a Bibliometria representa uma ferramenta importante no momento de apoiar a tomada de decisão. Considera-se que a realização de um estudo bibliométrico por meio da análise das citações utilizadas na elaboração de teses acadêmicas constitui ferramenta importante para apoiar a tomada de decisão quanto ao desenvolvimento de coleções de bibliotecas universitárias, pois, a partir das inferências feitas, podem ser definidas diretrizes para apoiar este processo.

Estudos bibliométricos, quando aplicados da forma aqui proposta, são uma das atividades que buscam desenvolver e controlar o conhecimento dentro da biblioteca. Estes estudos fazem parte da etapa responsável pela análise do ambiente, tendo como meta principal oferecer informações confiáveis para apoiar o processo decisório.

\section{Análise de citações e desenvolvimento de coleções}

Algumas metodologias tentam identificar a relevância das coleções existentes estudando a circulação e o uso dos materiais disponíveis na biblioteca, e, entre elas, destaca-se a análise de citações que se aplica perfeitamente às coleções de bibliotecas universitárias ou especializadas.

Destaca-se aqui o método estruturalista defendido por Baughman (1977; 1976), que permite um monitoramento do uso da coleção e dos ambientes para operacionalizar o desenvolvimento de coleções por meio de estudos empíricos. O método consiste em mapear o relacionamento entre: (I) o uso; (II) o conjunto de demandas em potencial; e (III) a Biblioteconomia. Segundo o autor, o desenvolvimento de coleções se encontra na interseção entre: (a) o planejamento, ou na intenção de adquirir os materiais informacionais de acordo com as metas, objetivos e prioridades da biblioteca e seus usuários; (b) a implementação, ou o ato de disponibilizar os materiais adquiridos; e (c) a avaliação, do alcance, ou não, das metas, objetivos e prioridades estabelecidas.

Baughman (1977; 1976) utilizou a bibliometria para elaborar sua investigação sobre a literatura de Sociologia para analisar a idade dos materiais, o idioma mais utilizado, os possíveis assuntos relacionados e os núcleos de publicadores. Na abordagem estruturalista, o monitoramento do uso e das demandas permite ao bibliotecário tomar decisões quanto ao desenvolvimento de coleções, pois associa o uso efetivo à demanda potencial.

Regressando à realidade brasileira, encontra-se a proposta metodológica de Oliveira (2004) para um sistema interativo de sugestões de aquisição de livros utilizando a análise de citações, baseada nos indicativos de demandas dos próprios usuários, em seus trabalhos científicos. A proposta mostra-se excelente, entretanto, pretende-se que a utilização de um estudo analítico das citações utilizadas nas teses tenha 
uma aplicação mais abrangente, não se restringindo a uma lista de sugestões de livros para aquisição.

Diversos autores detêm-se nas utilidades e limitações da análise de citações como apoio à tomada de decisão, no desenvolvimento de coleções. Segundo Broadus (1977), em uma situação ideal, o desenvolvimento de coleções deve ser executado por um bibliotecário que seja também especialista no assunto, porém, na ausência desse profissional, a análise de citações pode fornecer uma orientação útil para o bibliotecário não especializado.

A utilização da frequência de citações pode determinar a seleção da coleção-núcleo dos periódicos, mas pode ser considerada insuficiente para determinar todas as seleções (GARFIELD, 1977). Contudo, listas de periódicos oriundas dos estudos de citações não devem representar o fator preponderante no momento da compra, mas podem ser úteis para identificar os periódicos que devem ter avaliação mais acurada pelos bibliotecários familiarizados com as demandas de seus usuários (LINE, 1978).

Smith (1981) esclarece que a citação não é responsável pela qualidade ou importância dos materiais citados, e Spinak (1998, p. 144, tradução nossa) concorda quando afirma que "[...] os números refletem a quantidade ou atividade e de certa maneira a produtividade, mas não a qualidade e conteúdo das publicações".

Também se pode considerar que a validade de examinar as citações como medida de qualidade requer sua classificação em pelo menos três grupos: essenciais, suplementares e negativas (MEADOWS, 1999). Inclusive, porque, ao fazer uma citação, o autor pode ter outras motivações que não a simples fundamentação fática e/ou teórica de uma afirmativa, tais como: citação-recompensa, citação política, citação-álibi, citação-persuasão e a auto citação (LE COADIC, 2004).

Lancaster (2004) declara método de validade duvidosa avaliar o acervo de uma biblioteca universitária com base nas referências contidas em suas teses. Seu argumento baseia-se em um comportamento denominado "princípio do menor esforço", ou seja, quanto mais acessível for uma fonte de informação, maior a probabilidade de ela ser citada. As pesquisas em que Lancaster se baseia para esta declaração são da década de 60 e 70, do século passado, e a edição em língua inglesa de seu livro tem copyright de 1993. Sendo assim, acredita-se que no século XXI o acesso facilitado à informação pela Internet nos meios acadêmicos tenha superado este princípio.

Muito embora apresente limitações, o estudo analítico das citações revela-se uma interessante ferramenta de apoio às decisões administrativas, pois permite: (a) analisar atividades de pesquisa realizadas na instituição (SMITH, 1981); (b) distribuir os recursos financeiros disponíveis para investimento entre a coleção de periódicos e a de monografias (DEVIN; KELLOG, 1990); (c) decidir sobre a gerência da coleção (GREENE, 1993); (d) avaliar o uso de uma coleção de periódicos (SYLVIA, 1998); (e) escolher o tipo de material, por exemplo, literatura cinzenta, que deve fazer parte da coleção da biblioteca (URBANO SALIDO, 
2000); (f) armazenar a coleção em depósitos por sua antiguidade (ACKERSON, 2001); (g) selecionar os idiomas das obras que farão parte do acervo (KNIEVEL; KELLSEY, 2005); e (h) estudar os usuários como um método indireto de análise (URBANO SALIDO, 2001).

Percebe-se que as utilidades arroladas anteriormente encontram-se dispersas na literatura, resultado de diferentes estudos, em diferentes épocas. Destaca-se aqui a intenção desta pesquisa de reuni-las em uma única investigação.

\subsection{Análise de citação como método de estudo do usuário}

De acordo com Weitzel (2006, p. 21), "os estudos da comunidade são instrumentos importantes para a administração de bibliotecas de um modo geral e para o processo de desenvolvimento de coleções em particular". Estudos da comunidade ou estudo de usuários podem ser classificados como orientados ao uso, orientados ao usuário, básicos e/ou aplicados. Neste âmbito, a análise de citações de teses é considerada um estudo básico orientado ao uso, pois visa a obter conhecimento sobre o padrão de comunicação do usuário interno da biblioteca (DIAS, PIRES, 2004).

$\mathrm{Na}$ literatura, são encontrados alguns autores que consideram possível estudar a comunidade usuária pela análise das citações oriundas das teses e dissertações, pois esta análise pode servir como método indireto de estudo do usuário, dado que este tipo de investigação permite desenvolver estruturas teóricas a respeito da expectativa do uso dos materiais futuros, baseados nos critérios comuns dos materiais já utilizados (KOVACS, 1990; SMITH, 1981; TARAPANOFF; MIRANDA; ARAÚJO JÚNIOR, 2004; TUÑÓN BRYDGES, 2005; URBANO SALIDO, 2001).

Acredita-se também que sejam particularmente atraentes, pois as respostas obtidas a partir da análise das citações utilizadas na elaboração das teses apresentam a vantagem de não serem contaminadas por opiniões dos usuários participantes da investigação. Além disso, as informações podem ser descritas, contadas e os dados podem ser coletados com relativa facilidade (TUÑóN; BRYDGES, 2005). Nesta circunstância, o bibliotecário instrumentaliza-se para o planejamento do desenvolvimento de coleções em bibliotecas universitárias, funcionando como um mecanismo que permite adequar a coleção às demandas informacionais de seus usuários.

\section{Procedimentos de coleta dos dados}

O primeiro passo para obter os dados empíricos da pesquisa foi a consulta ao banco de dados, que mantém os dados catalográficos de todas as teses defendidas na UFRGS, o SABi. Para pertencer ao universo da investigação a tese cujas citações serão investigadas deve ter sido defendida no PPGA/ EA/UFRGS de 1999, ano da primeira defesa, até 2007; e ter sido orientada por professores pertencentes ao Departamento 
de Ciências Administrativas (DCA). Foram recuperadas 85 teses que obedeciam aos critérios estabelecidos para esta pesquisa.

Ao tabular os resultados da busca no $\mathrm{SABi}$, percebeu-se que a definição da amostra seria complexa, pois a distribuição das 85 teses se apresentava de forma irregular quanto ao ano de defesa e à área de concentração, como pode ser visualizado na TAB. 1. Atualmente, o PPGA encontra-se estruturado em seis áreas de concentração, a saber: Contabilidade e Finanças (CF); Gestão da Tecnologia e da Produção (GTP); Marketing (MKT); Organizações (ORG); Recursos Humanos (RH); e Sistemas de Informação e de Apoio à Decisão (SIAD).

TABELA 1 Teses defendidas no PPGA/EA/UFRGS por ano e por área de concentração

\begin{tabular}{|c|c|c|c|c|c|c|c|c|c|c|c|}
\hline \multirow{2}{*}{$\begin{array}{c}\text { ÁREA } \\
\text { CONCENTRAÇÃOO }\end{array}$} & \multicolumn{9}{|c|}{ ANO } & \multirow{2}{*}{ TOTAL } & \multirow{2}{*}{$(\%)$} \\
\hline & 1999 & 2000 & 2001 & 2002 & 2003 & 2004 & 2005 & 2006 & 2007 & & \\
\hline GTP & 1 & 1 & 2 & 2 & 0 & 4 & 6 & 7 & 0 & 23 & 27,06 \\
\hline MKT & 1 & 1 & 3 & 1 & 1 & 2 & 4 & 3 & 2 & 18 & 21,18 \\
\hline SIAD & 2 & 3 & 2 & 0 & 0 & 2 & 3 & 4 & 0 & 16 & 18,82 \\
\hline ORG & 0 & 1 & 1 & 1 & 2 & 2 & 3 & 3 & 1 & 14 & 16,47 \\
\hline RH & 0 & 2 & 4 & 0 & 0 & 1 & 2 & 0 & 2 & 11 & 12,94 \\
\hline $\mathrm{CF}$ & 0 & 0 & 0 & 0 & 0 & 0 & 2 & 1 & 0 & 3 & 3,53 \\
\hline TOTAL & 4 & 8 & 12 & 4 & 3 & 11 & 20 & 18 & 5 & 85 & 100 \\
\hline$(\%)$ & 4,71 & $\mathbf{9 , 4 1}$ & 14,12 & 4,71 & $\mathbf{3 , 5 3}$ & 12,94 & 23,53 & 21,18 & 5,88 & 100 & \\
\hline
\end{tabular}

Fonte: Dados da pesquisa.

A distribuição temporal dos dados revela grande variabilidade tanto por área de concentração, quanto no total. Por área de concentração, GTP lidera o total de teses defendidas, enquanto MKT apresenta maior regularidade com pelo menos uma tese defendida por ano. CF apresenta a menor frequência de tese por área, concentrando suas defesas nos anos de 2005 e 2006.

Entretanto, no total se percebe substancial evolução nas teses defendidas em relação a 1999, ainda que com alguma irregularidade para cima (2005 e 2006) e para baixo (2002, 2003 e 2007). Tais padrões podem ser atribuídos à complexidade do processo de elaboração de uma tese, no caso geral; e às especificidades de cada linha de pesquisa, nos casos específicos.

Reunidas as informações sobre cada uma das 85 teses, tabulou-se 13.298 citações utilizadas, cuja distribuição por área de concentração está sumariada na TAB. 2. 
TABELA 2 Citações utilizadas nas teses defendidas no PPGA/EA/UFRGS por área de concentração

\begin{tabular}{lrrrrr}
\hline \multirow{2}{*}{ ÁREA CONCENTRAÇÃO } & \multicolumn{2}{c}{ TESES } & \multicolumn{2}{c}{ CITAÇõES } \\
\cline { 2 - 5 } & FREQ. & $(\boldsymbol{\%})$ & FREQ. & $(\boldsymbol{\%})$ \\
\hline GTP & 23 & 27,06 & 3568 & 26,83 \\
MKT & 18 & 21,18 & 2903 & 21,83 \\
SIAD & 16 & 18,82 & 2108 & 15,85 \\
ORG & 14 & 16,47 & 2276 & 17,12 \\
RH & 11 & 12,94 & 2142 & 16,11 \\
CF & 3 & 3,53 & 301 & 2,26 \\
\hline TOTAL & $\mathbf{8 5}$ & $\mathbf{1 0 0}$ & $\mathbf{1 3 2 9 8}$ & $\mathbf{1 0 0}$ \\
\hline
\end{tabular}

Fonte: Dados da pesquisa.

Considerando-se as observações de Vieira (2003) sobre parâmetro e estimativa usados nas técnicas de definição de amostragem na estatística descritiva, assim como o alerta de Oliveira e Grácio (2005) sobre os procedimentos estatísticos para a determinação do tamanho de uma amostra casual simples, decidiu-se utilizar um procedimento de recenseamento do objeto de estudo com a inclusão de todas as citações das teses disponíveis na ocasião da coleta dos dados, considerado material empírico adequado para a investigação.

\section{Análise dos dados}

Com a intenção de obter um panorama geral dos dados, iniciou-se o trabalho pela apresentação da estatística descritiva das citações utilizadas nas teses. Na TAB. 3 é possível visualizar a média, a variância, o coeficiente de variação e o máximo e o mínimo das citações por ano de defesa da tese.

TABELA 3 Estatística descritiva das citações utilizadas nas teses defendidas no PPGA/EA/UFRGS por ano

\begin{tabular}{lrrrrrrrrr}
\hline \multirow{2}{*}{ CITAÇÕES } & \multicolumn{10}{c}{ ANO DE DEFESA DA TESE } \\
\cline { 2 - 9 } & $\mathbf{1 9 9 9}$ & $\mathbf{2 0 0 0}$ & $\mathbf{2 0 0 1}$ & $\mathbf{2 0 0 2}$ & $\mathbf{2 0 0 3}$ & $\mathbf{2 0 0 4}$ & $\mathbf{2 0 0 5}$ & $\mathbf{2 0 0 6}$ & $\mathbf{2 0 0 7}$ \\
\hline $\bar{X}$ & 150,50 & 167,75 & 166,67 & 146,50 & 216,67 & 163,36 & 154,00 & 138,78 & 148,60 \\
S & 42,97 & 71,33 & 50,21 & 55,29 & 40,50 & 110,00 & 52,02 & 58,13 & 109,54 \\
C. V. & 0,29 & 0,43 & 0,30 & 0,38 & 0,19 & 0,67 & 0,34 & 0,42 & 0,74 \\
MAX & 213 & 337 & 242 & 211 & 257 & 455 & 222 & 280 & 336 \\
MIN & 115 & 114 & 102 & 87 & 176 & 84 & 32 & 69 & 61 \\
\hline
\end{tabular}

Fonte: Dados da pesquisa.

A TAB. 3 mostra que há variabilidade temporal também nas citações. Em média, as citações variam de 138,78 em 2006, a 216,67 em 2003, com substancial dispersão em cada ano, como mostra o desvio padrão, que varia de 40,50 em 2003, a 109,54 em 2007. O máximo e o mínimo de citações ajudam a completar o panorama da dispersão das referências utilizadas. O máximo de referências varia de 211 em 2002, a 455 em 2004; e o mínimo varia de 32 em 2005, a 176 em 2003.

O coeficiente de variação permite a comparação entre variáveis com diferentes unidades de medida e, neste caso, revela que os anos de 1999 
e 2001 tiveram um comportamento similar, pois o coeficiente de variação é muito próximo: respectivamente, 0,29 e 0,30. A mesma avaliação serve para os anos de 2000 e 2006 que apresentam coeficientes de variação 0,43 e 0,42. Os anos de 2004 e 2007, que apresentam um coeficiente de variação alto, de 0,67 e 0,74, respectivamente, evidenciam um uso do material informacional muito acima dos outros anos.

Em suma, com exceção do ano de 2003, que apresenta um uso menos disperso dos documentos, como indicam o coeficiente de variação $(0,19)$ e o desvio padrão $(40,50)$, via de regra, não se encontrou um padrão de comportamento de uso do material informacional nos autores das teses, dificultando o planejamento e a alocação de recursos. Mas será que é possível identificar qual área do conhecimento é responsável pelo uso deste material informacional acima da média? A TAB. 4 mostra a tabulação dos dados por área de concentração.

TABELA 4 Estatística descritiva das citações utilizadas nas teses defendidas no PPGA/EA/UFRGS de 1999 até 2007 por área de concentração

\begin{tabular}{lrrrrrr}
\hline \multirow{2}{*}{ CITAÇÕES } & CF & \multicolumn{7}{c}{ GTP } & MKT & ORG & RH & SIAD \\
\cline { 2 - 7 } & \multicolumn{1}{c}{ ORE DONCENTRAC̃O } \\
\hline $\bar{X}$ & 100,33 & 155,13 & 161,28 & 162,57 & 194,73 & 131,75 \\
S & 43,36 & 49,53 & 61,00 & 77,48 & 107,40 & 43,80 \\
C. V. & 0,43 & 0,32 & 0,38 & 0,48 & 0,55 & 0,33 \\
MAX & 150 & 261 & 336 & 280 & 455 & 224 \\
MIN & 70 & 87 & 69 & 61 & 111 & 32 \\
\hline
\end{tabular}

Fonte: Dados da pesquisa.

Verifica-se que duas áreas apresentam alto coeficiente de variação: RH com 0,55 e ORG com 0,48. De fato, a média de citações utilizadas na elaboração das teses destas áreas está acima das outras, revelando que estas são as áreas com maior demanda informacional. Observando-se os mesmos indicadores, percebe-se que GTP e SIAD são as áreas em que os autores apresentam um uso mais parcimonioso dos itens informacionais, visto que apresentam baixo coeficiente de variação.

Vale observar que, sem considerar o coeficiente de variação, fica-se com a percepção distorcida de que a área de CF tem indicadores mais parcimoniosos que GTP, o que não ocorre, porquanto CF apresenta a menor média, o menor desvio padrão e a menor máxima das áreas estudadas, mas seu coeficiente de variação é alto: 0,43.

Criam-se, dessa forma, categorias de uso dos itens informacionais. Ou seja, nos estudos que utilizam análise de citações de teses como apoio à tomada de decisão em desenvolvimento de coleções e que envolvam diferentes áreas e subáreas do conhecimento; pode-se classificar o coeficiente de variação resultante da estatística descritiva de cada área ou subárea numa ordem decrescente, dividindo-os em pelo menos três categorias de uso, a saber: (a) o coeficiente de variação com valor mais alto representa a categoria uso intenso dos itens informacionais; (b) 0 coeficiente de variação que apresenta seu valor entre o mais alto e o mais 
baixo, representa a categoria uso intermediário dos itens informacionais; e (c) o coeficiente de variação com valor mais baixo representa a categoria uso parcimonioso dos itens informacionais.

O grau de dificuldade do processo de desenvolvimento de coleções de determinada área ou subárea será proporcional à categoria de uso a qual ela pertence. O QUAD. 1 mostra as áreas de concentração do PPGA/EA/UFRGS e suas respectivas categorias de uso dos itens informacionais, de acordo com a tabulação dos dados da pesquisa.

QUADRO 1 Categorias de uso informacional por área de concentração do PPGA/EA/UFRGS

\begin{tabular}{|l|c|r||}
\hline \hline ÁREAS & COEFICIENTE DE VARIAÇÃO & CATEGORIA \\
\hline RH & 0,55 & Uso intenso \\
\hline ORG & 0,48 & Uso intermediário \\
\hline CF & 0,43 & Uso parcimonioso \\
\hline MKT & 0,38 & \\
\hline SIAD & 0,33 & \\
\hline GTP & 0,32 & \\
\hline
\end{tabular}

Fonte: Dados da pesquisa.

Dado este panorama geral, passou-se para a análise das citações pela tipologia dos materiais, seguida da análise acerca da idade da literatura dos documentos, dos títulos dos periódicos citados e das preferências dos idiomas dos materiais consultados pelos autores das teses. Para classificar as referências foi elaborada uma lista de possíveis tipologias, de acordo com as normas para elaboração de referências da Associação Brasileira de Normas Técnicas (2002), que norteiam a descrição das referências citadas nas teses estudadas.

\subsection{Tipologia}

Encontrou-se 29 tipologias entre as 13.298 citações empregadas nas teses pesquisadas. Para melhorar a análise, agruparam-se os materiais informacionais semelhantes, independentemente de seu suporte físico. Entre os dados agrupados, destacam-se três tipos de documentos mais utilizados na elaboração das teses: livros, publicação periódica e anais de evento, que juntos representam $91,34 \%$ da população estudada.

TABELA 5 Tipologia dos documentos utilizados na elaboração das teses defendidas no PPGA/EA/UFRGS de 1999 até 2007 agrupados

\begin{tabular}{lrrrr}
\hline \multirow{2}{*}{ TIPOLOGIA } & \multicolumn{4}{c}{ FREQÜÊECIA } \\
\cline { 2 - 5 } & SIMPLES & $(\boldsymbol{\%})$ & ACUM. & $\mathbf{( \% )}$ \\
\hline Livro e capítulo de livro impresso e eletrônico & 6259 & 47,06 & 6259 & 47,06 \\
Publicação periódica impressa e eletrônica & 5068 & 38,10 & 11327 & 85,16 \\
& & & & \\
Anais de evento impresso e eletrônico & 819 & 6,16 & 12146 & 91,32 \\
Site & 467 & 3,51 & 12613 & 94,83 \\
Demais materiais & 685 & 5,17 & 13298 & 100 \\
\hline TOTAL & $\mathbf{1 3 2 9 8}$ & $\mathbf{1 0 0}$ & $\mathbf{1 3 2 9 8}$ & $\mathbf{1 0 0}$ \\
\hline
\end{tabular}

Fonte: Dados da pesquisa. 
Este percentual pode sugerir que a distribuição dos recursos financeiros disponíveis para investimento em inclusão, substituição ou prioridades na coleção geral da biblioteca devam ser feitas na mesma proporção da ocorrência das tipologias. Entretanto, tornou-se necessário verificar se o comportamento da amostra se revelava idêntico em cada uma das áreas de concentração do PPGA. Assim, tabulou-se de forma agregada a tipologia dos documentos em cada área de concentração para confirmar, ou não, o comportamento verificado.

As áreas de GTP, ORG e RH reproduzem o comportamento da amostra estudada: uso preferencial de livros seguidos de publicações periódicas na elaboração das teses. Nas áreas de CF, MKT e SIAD há o inverso: uma preferência pelo uso da publicação periódica seguida do livro.

Desta forma, deve-se ter cuidado ao distribuir os recursos financeiros disponíveis para inclusão, substituição e prioridades na coleção, respeitando estas peculiaridades. O uso de sites como material informacional na elaboração das teses destacou-se em três áreas: GTP, MKT e SIAD. Verificou-se também se a preferência pela tipologia do material apresentava-se como um comportamento ao longo dos anos estudados. Constatou-se que no ano de 2005 foi maior o uso de publicações periódicas $(44,06 \%)$. Nos demais anos, foram utilizados preferencialmente livros na elaboração das teses.

Entende-se que a análise dos dados da pesquisa por tipologia corrobora as afirmações de Devin e Kellog (1990), possibilitando distribuir os recursos financeiros disponíveis para investimento de forma eficaz. Considera-se também que os dados tabulados permitem escolher o tipo de material que deve fazer parte da coleção, como destacou Urbano Salido (2000).

\subsection{Idade da literatura}

Optou-se por utilizar o termo idade da literatura ao invés do termo obsolescência comumente usado. Esta opção deve-se à concordância com Tarapanoff, Miranda e Araújo Júnior (2004, p. 95) quando argumentam que não se pode afirmar com exatidão que determinado documento se tornou obsoleto só por ele ter caído em desuso, considerando, assim, que os conceitos que ele contém não possuem mais validade. "Nesse sentido, a expressão mais adequada para definir a perda de representatividade [do item informacional] é idade da literatura".

Segundo Gapen e Milner (1981), a idade da literatura é um assunto de interesse prático para bibliotecários que administram coleções crescentes em espaços finitos, pois apesar da previsão acerca das alterações que os avanços tecnológicos provocariam nos dispositivos de armazenamento e consequentemente no depósito das informações nas bibliotecas, ela ocorreu somente para alguns tipos de materiais informacionais, como periódicos científicos; e alguns tipos de bibliotecas, como as universitárias. 
Line (1993) afirma que pouca investigação foi levada a cabo em situações reais de bibliotecas, e que a maioria dos estudos sobre idade da literatura aborda citações de periódicos, provavelmente devido aos índices de citação que facilitam este tipo de investigação. Todavia, de forma pouco usual, esta pesquisa se propõe a avaliar a idade da literatura em uma situação real de biblioteca.

A TAB. 6 apresenta um panorama geral da idade da literatura das citações das teses estudadas. Os materiais citados encontram-se concentrados na década de 1990, com 50,73\%, e no período de 2000 até 2007, com 25\% do total dos dados tabulados. Excepcionalmente, uma das referências utilizadas reporta-se ao livro A Riqueza das Nações, de Adam Smith, com data de 1776*. Como a referência encontra-se na língua portuguesa, acredita-se ter ocorrido um equívoco na descrição do material, entretanto não se entrou no mérito do conteúdo das referências.

TABELA 6 Idade da literatura dos documentos utilizados na elaboração das teses do PPGA/EA/UFRGS defendidas de 1999 até 2007

\begin{tabular}{lrr}
\hline ANO DA CITAÇÃO & FREQÜÊNCIA & $(\boldsymbol{\%})$ \\
\hline Antes de $1979^{*}$ & 1101 & 8,28 \\
De 1980 até 1989 & 1935 & 14,55 \\
De 1990 até 1999 & 6746 & 50,73 \\
De 2000 até 2007 & 3324 & 25,00 \\
Não definida & 192 & 1,44 \\
\hline TOTAL & $\mathbf{1 3 2 9 8}$ & $\mathbf{1 0 0}$ \\
\hline
\end{tabular}

Fonte: Dados da pesquisa.

A análise dos dados tabulados permite sugerir que os materiais informacionais com datas anteriores a 1989 sejam armazenados de forma organizada, em espaço físico separado, constituindo um acervo fechado com acesso intermediado pelo pessoal da biblioteca. Assim, libera-se mais espaço no salão principal para a coleção com acesso livre, permitindo um crescimento confortável do acervo e melhorando a circulação dos usuários no local.

De acordo com Genoni (2008), o problema de armazenamento e eliminação de material informacional impresso em desuso vem sendo estudado nos Estados Unidos da América, Reino Unido e Austrália. O resultado da pesquisa nas bibliotecas acadêmicas australianas traz algumas indicações, como: (a) a grave escassez de espaço físico para armazenamento das coleções impressas; (b) a incerteza quanto ao planejamento sobre este assunto para o futuro; (c) muitas dúvidas quanto ao modo de hierarquizar o material para armazenamento ou eliminação apresentando ambivalência, por exemplo, em relação à necessidade de continuar a manter cópias impressas de periódicos que estão disponíveis eletronicamente; e (d) a busca da solução de armazenamento por meio da cooperação.

Analisando-se os dados desta pesquisa quanto à idade da literatura, pode-se afiançar que o estudo analítico das citações realmente se revela uma ferramenta útil no apoio de decisões administrativas sobre a gerência da coleção, tal como afirmaram Greene (1983) e Ackerson (2001). 


\section{3 títulos de periódicos}

O resultado da análise dos periódicos citados pelos autores das teses estudadas pode determinar quais títulos devem formar a coleção-núcleo da BSEA, além de fornecer importantes informações no momento de tomar a decisão quanto ao investimento do orçamento da biblioteca.

De acordo com Sylvia (1998), é possível avaliar o uso de uma coleção de periódicos pelo estudo analítico das citações, tarefa também empreendida por Vallmitjana e Sabaté (2008) que nos apresentam uma matriz comparativa de diversos trabalhos que utilizam a análise de citação de teses como ferramenta para avaliar as demandas de informação dos pesquisadores.

Acrescentou-se à matriz de Vallmitjana e Sabaté (2008) os dados desta investigação visando a indicar que ela se encontra dentro de um padrão internacional, como pode ser visualizado no QUAD.2.

QUADRO 2 Resumo comparativo de estudos sobre análise de citação de teses

\begin{tabular}{||c|c|c|c|c|c|c|c|c||}
\hline \hline \multirow{2}{*}{ DADOS } & \multicolumn{9}{|c||}{ AUTORES } \\
\cline { 2 - 10 } & Buchanan & Buttlar & Gooden & Haycock & Kushkowski & Smith & Vallmitjana & Mattos \\
\hline País & USA & USA & USA & USA & USA & USA & Espanha & Brasil \\
\hline Área & $\begin{array}{c}\text { Ciência } \\
\text { Política }\end{array}$ & $\begin{array}{c}\text { Bibliotec. e } \\
\text { Ciência da } \\
\text { Inf. }\end{array}$ & Química & Educação & Multidiscip. & $\begin{array}{c}\text { Multidisc } \\
\text { ip. }\end{array}$ & Química & Administr. \\
\hline Período & $1979-1989$ & $1994-1997$ & $1996-2000$ & $2000-2002$ & $1973-1992$ & 2001 & $1995-2003$ & $1999-2007$ \\
\hline $\begin{array}{c}\text { Número } \\
\text { teses }\end{array}$ & 32 & 61 & 30 & 43 & 629 & 30 & 46 & 85 \\
\hline $\begin{array}{c}\text { Número } \\
\text { citações }\end{array}$ & 3.673 & 3.683 & 3.704 & 4.542 & 9.100 & 1.595 & 5.320 & 13.298 \\
\hline $\begin{array}{c}\text { Artigos } \\
\text { (\%) }\end{array}$ & 37 & 46 & 86 & 44 & 64 & 48 & 79 & 38 \\
\hline $\begin{array}{c}\text { Número } \\
\text { periódicos }\end{array}$ & 327 & 815 & 441 & 558 & $\begin{array}{c}\text { Não } \\
\text { apresenta }\end{array}$ & $\begin{array}{c}\text { Não } \\
\text { apresenta }\end{array}$ & 593 & 1131 \\
\hline \hline
\end{tabular}

Fonte: Adaptado de VALLMITJANA; SABATÉ (2008, p. 79)

Destaca-se ali a pesquisa de Buchanan, desenvolvida nos USA, utilizando as teses de Ciência Política publicadas de 1979 até 1989, por guardar similaridade com este estudo quanto ao percentual de uso de artigos de periódicos na elaboração das teses, $37 \%$ e $38 \%$, respectivamente. Ambos os estudos também revelam semelhança na proporção do uso de periódicos na sua relação com o número total de citações utilizadas na elaboração das teses: $8,9 \%$ no caso norteamericano e $8,5 \%$ no caso brasileiro.

Identificaram-se os títulos dos periódicos mais citados pelos autores das teses estudadas. O banco de dados revelou um conjunto de 5.068 citações de periódicos utilizadas na elaboração das 85 teses estudadas, que se encontram distribuídos entre 1.131 títulos. A observação dos dados revela que a relação encontrada entre o número de citações e o número de periódicos é de 4,48, e a média de artigos citados por tese é de 59,62.

Uma vez identificados os títulos dos artigos citados na elaboração das teses que fazem parte desta pesquisa, utiliza-se a Lei de Bradford 
(1985) para determinar a coleção núcleo de periódicos, dividindo o resultado apurado em três zonas:

a) a primeira zona apresenta 33,27\% das citações, ou 1.686 citações distribuídas em 17 títulos, ou $1,53 \%$ dos periódicos da especialidade. São pouco numerosos e possuem artigos relevantes para a formação de um acervo sobre o assunto. Aqui a relação entre o número de citações e o número de periódicos é de 99,18;

b) na segunda zona encontram-se 33,64\% das citações, ou 1.705 citações distribuídas em 115 títulos, ou 10,20\% dos periódicos que não são da especialidade, mas possuem conteúdo que abarca o núcleo da literatura. Aqui a relação entre o número de citações e o número de periódicos é de 14,82; e

c) a terceira zona apresenta 33,09\% das citações, ou 1677 citações distribuídas em 999 títulos, ou 88,27\% dos periódicos que possuem relação remota com a especialidade examinada. Aqui a relação entre o número de citações e o número de periódicos é de 1,67.

$\mathrm{Na}$ perspectiva de um equilíbrio entre as diferentes áreas de concentração do PPGA, passou-se a analisar os periódicos por área, colocando-se uma lupa sobre os títulos apurados na primeira zona do panorama geral, reunindo-os com os títulos das primeiras zonas apurados nas seis áreas de concentração, formando uma única lista com 72 títulos de periódicos. Procedeu-se, então, à eliminação dos títulos que se encontravam repetidos, restando, assim, 40 títulos que constituem a coleção núcleo, de acordo com os autores das teses estudadas.

Dessa forma, é fortemente recomendada a aquisição dos 40 títulos pertencentes à coleção-núcleo apurada neste estudo, após consulta ao Portal à época da aquisição para verificar sua disponibilidade e os períodos de embargo na ocasião. No presente, uma decisão quanto ao investimento do orçamento da biblioteca em publicações periódicas passa por uma análise da disponibilidade dos mesmos no Portal de Periódicos Capes, principal fonte de informação técnica e científica das Instituições de Ensino Superior no Brasil.

\subsection{Preferência dos idiomas}

Distinguindo-se a preferência dos idiomas apresentada nos documentos utilizados na elaboração das teses estudadas, pode-se inferir quais deles devem ocorrer nos materiais bibliográficos selecionados em futuras aquisições por compra, doação ou permuta.

A tabulação dos dados da amostra estudada, visualizados na TAB. 7, demonstrou uma preferência pela língua inglesa representando $54,75 \%$, seguida pela portuguesa com $40,26 \%$ e a ocorrência $4,99 \%$ de outros idiomas. Este resultado confirma o que foi determinado na Política de Seleção da Biblioteca Setorial da EA, editada em 2006, que dá preferência ao idioma português seguido do inglês. 
TABELA 7 Idioma dos documentos utilizados na elaboração das teses defendidas no PPGA/EA/UFRGS de 1999 até 2007

\begin{tabular}{lrr}
\hline IDIOMA & FREQÜ̂̂NCIA & $(\boldsymbol{\%})$ \\
\hline Inglês & 7280 & 54,75 \\
Português & 5355 & 40,26 \\
Francês & 339 & 2,55 \\
Espanhol & 299 & 2,25 \\
Outros & 13 & 0,10 \\
Italiano & 7 & 0,05 \\
Alemão & 5 & 0,04 \\
\hline TOTAL & $\mathbf{1 3 2 9 8}$ & $\mathbf{1 0 0}$ \\
\hline
\end{tabular}

Fonte: Dados da pesquisa.

A verificação dos idiomas preferenciais utilizados pelos autores das teses ao elaborá-las levou a outra questão: Em que tipo de material informacional ocorre determinado idioma? A TAB. 8 apresenta os dados que respondem a esta indagação.

TABELA 8 Tipos de documentos versus idiomas utilizados na elaboração das teses defendidas no PPGA/EA/UFRGS de 1999 até 2007

\begin{tabular}{llrr}
\hline TIPOLOGIA & IDIOMA & FREQ. & $\mathbf{( \% )}$ \\
\hline \multirow{2}{*}{ Livro } & Português & 3320 & 53,04 \\
& Inglês & 2511 & 40,12 \\
\hline SUBTOTAL & Outros & 428 & 6,84 \\
\hline \multirow{2}{*}{ Publicação periódica } & & $\mathbf{6 2 5 9}$ & $\mathbf{1 0 0}$ \\
& Inglês & 4232 & 83,50 \\
SUBTOTAL & Português & 734 & 14,48 \\
\hline \multirow{2}{*}{ Anais de evento } & Outros & 102 & 2,02 \\
& & $\mathbf{5 0 6 8}$ & $\mathbf{1 0 0}$ \\
\hline SUBTOTAL & Português & 497 & 60,68 \\
& Inglês & 300 & 36,63 \\
Sites & Outros & 22 & 2,69 \\
\hline SUBTOTAL & & $\mathbf{8 1 9}$ & $\mathbf{1 0 0}$ \\
\hline \multirow{2}{*}{ Outros } & Português & 232 & 49,68 \\
& Inglês & 143 & 30,62 \\
& Outros & 92 & 19,70 \\
\hline SUBTOTAL & & $\mathbf{4 6 7}$ & $\mathbf{1 0 0}$ \\
\hline TOTAL & Português & 572 & 83,50 \\
\hline
\end{tabular}

Fonte: Dados da pesquisa.

Nossa análise concentra-se nos três tipos de materiais mais utilizados. Os anais de evento $(60,68 \%)$ e os livros $(53,04)$ apresentam maior frequência em língua portuguesa. Entretanto, a ocorrência de $40,12 \%$ de livros em língua inglesa deve ser considerada no momento de seleção de novos materiais que farão parte da coleção. Já dentre as publicações periódicas há um grande destaque da língua inglesa com $83,5 \%$ das ocorrências. 


\section{Conclusão}

Apresentou-se um estudo fundamentado em autores cuja produção científica vem contribuindo, significativamente, para que se analise o papel dos estudos métricos na produção e avaliação científica.

Julga-se que os resultados apresentados tenham atingido os objetivos desta investigação com êxito, além de produzir uma reflexão teórica sobre as questões relacionadas ao significado da ligação entre a produção científica registrada e o processo de tomada de decisões na formação das coleções de bibliotecas universitárias.

Além disso, indiretamente, realizou-se uma reflexão sobre o difícil processo de avaliação dos programas de pós-graduação, considerando que cada área do conhecimento, e neste caso, uma única disciplina, tem domínios e especificidades que se precisa reconhecer e caracterizar.

Muitas bibliotecas acadêmicas começaram a observar as citações apresentadas nas teses produzidas por seus alunos como evidência das habilidades desenvolvidas por eles para pesquisar. Elas também servem como um indicador parcial da qualidade das obras utilizadas por eles na elaboração de suas monografias. Estudá-las, tem ajudado as bibliotecas universitárias a conduzir o desenvolvimento de suas coleções.

Por fim, encontraram-se as respostas para os dois problemas de pesquisa:

a) sim, os usuários, alunos de doutorado em Administração estudados comportam-se de maneira diferenciada no uso da informação, sendo possível, inclusive, categorizá-los (intenso, intermediário e parcimonioso); e

b) sim, as referências citadas nas teses são indicadores representativos que servem de base para a elaboração de uma política de desenvolvimento de coleções, repercutindo, inclusive, na sua atualização.

\section{Referências}

ACKERSON, L. G. Is age an appropriate criterion for moving journals to storage? Collection Management: devoted to the management of library collections, New York, v. 26, n. 3, p. 63-76, 2001.

ASSOCIAÇÃO BRASILEIRA DE NORMAS TÉCNICAS (ABNT). NBR 6023: informação e documentação - referências - elaboração. Rio de Janeiro, 2002.

BAUGHMAN, J. C. A structural analysis of the literature of sociology. The Library Quarterly, Chicago, v. 44, n. 4, p. 203-308, Oct. 1976.

BAUGHMAN, J. C. Toward a structural approach to collection development. College and Research Libraries, Chicago, v. 38, n. 3, p. 241-248, May 1977. 
BROADUS, R. N. The applications of citation analyses to library collection building. In: VOIGT, M. J.; HARRIS, M. H. (Editors). Advances in librarianship, New York: Academic Press, 1977. v. 7, p. 299-335.

BRADFORD, S. C. Sources of information on specific subjects 1934. Journal of Information Science, v. 10, n. 4, p. 176-180, 1985.

BUCHANAN, L.; O'CONNELL, A. A brief history of decision making. Harvard Business Review, Boston, v. 84, n. 1, p. 32-41, Jan 2006. Disponível em: $<$ http://www.hbrbr.com.br/textos.asp?codigo $=10503>$. Acesso em: 02 set. 2007.

CARVALHO, I. C. L. A socialização do conhecimento no espaço das bibliotecas universitárias. Niterói: Intertexto, 2004.

CUNHA, M. B. Construindo o futuro: a biblioteca universitária brasileira em 2010. Ciência da Informação, Brasília, DF, v. 29, n. 1, p. 719-89, jan./abr. 2000. Disponível em: <http://www.scielo.br/pdf/ci/v29n1/v29n1a8.pdf>. Acesso em: 30 set. 2008.

DEVIN, R. B.; KELLOG, M. The serial/monograph ratio in research libraries: budgeting in light of citation studies. College and Research Libraries, Chicago, v. 51, n. 1, p. 46-54, Jan. 1990. Disponível em: <http://vnweb.hwwilsonweb.com/hww/jumpstart.jhtml?recid=0bc05f7a67 b1790ef409bfd03ef7308d9cce0c69627ab8fb246c44637559a5b85fd2de26 95332b8e\&fmt=C>. Acesso em: 06 jul. 2006.

DIAS, E. W. Organização do conhecimento no contexto de bibliotecas tradicionais e digitais. In: NAVES, M. M. L.; KURAMOTO, H. (Org.). Organização da informação: princípios e tendências. Brasília, DF: Briquet de Lemos, 2006. p. 62-75.

DIAS, M. M. K.; PIRES, D. Usos e usuários da informação. São Carlos: EdUFSCar, 2004.

DIAS, M. M. K.; PIRES, D. Formação e desenvolvimento de coleções de serviços de informação. São Carlos: EdUFSCar, 2003.

FIGUEIREDO, N. M.; LIMA, R. C. M. Seleção e aquisição: da visão clássica à moderna aplicação de técnicas bibliométricas. In: FIGUEIREDO, N. M. de. Desenvolvimento \& avaliação de coleções. 2. ed. Brasília, DF: Thesaurus, 1998. p. 67-96.

FONSECA, E. N. Introdução à Biblioteconomia. 2. ed. Brasília, DF: Briquet de Lemos, 2007.

GAPEN, K.; MILNER, S. P. Obsolescence. Library Trends, Illinois, v. 30, n. 1, p. 107-124, Summer 1981.

GARFIELD, E. Is citation frequency a valid criterion for selecting journals? Essays of an Information Scientist, Philadelphia, v. 1, p. 289-290, 1977.

GENONI, P. Current and future print storage for Australian academic libraries: results of a survey. Library Collections, Acquisitions, \& Technical 
Services, v. 32, n. 1, p. 31-41, 2008. Disponível em: <www.elsevier.com/locate/lcats $>$. Acesso em: 02 out. 2008.

GREENE, R. J. Computer analysis of local citation information in collection management. Collection Management: devoted to the management of library collections, New York, v. 17, n. 4, p. 11-24, June 1993.

KNIEVEL, J. E.; KELLSEY, C. Citation analysis for collection development: a comparative study of eight humanities fields. The Library Quarterly, Chicago, v. 75, n. 2, p. 142-168, Apr. 2005. Disponível em: $<$ http://www.journals.uchicago.edu/LQ/journal/issues/v75n2/750203/750 203.web.pdf>. Acesso em: 17 jun. 2006.

KOVACS, B. Decision making in collection development literature. In: . The decision-making process for library collections: case studies in four types of libraries. New York: Greenwood, 1990. p. 12-22.

LANCASTER, F. W. Avaliação do acervo: análise de uso. In:

Avaliação de serviços de bibliotecas. Brasília, DF: Briquet de Lemos, 2004. p. 51-76.

LE COADIC, Y. A ciência da informação. 2. ed. Brasília, DF: Briquet de Lemos, 2004.

LINE, M. B. Rank lists based on citations and library uses as indicators of journal usage in individual libraries. Collection Management: devoted to the management of library collections, New York, v. 2, n. 4, p. 313-316, 1978.

LINE, M. B. Changes in the use of literature with time: obsolescence revisited. Library Trends, v. 41, n. 4, p. 665-683, Spring 1993.

MEADOWS, A. J. A comunicação científica. Brasília, DF: Briquet de Lemos, 1999.

MORIGI, V. J.; SOUTO, L. R. Entre o passado e o presente: as visões de biblioteca no mundo contemporâneo. Revista ACB: Biblioteconomia em Santa Catarina, v. 10, n. 2, p. 189-206, jan./dez. 2005.

OLIVEIRA, E. Identificando necessidades de acervo de usuários de um departamento acadêmico: uma abordagem bibliométrica. Ciência da Informação, Brasília, DF, v. 33, n. 1, p. 126-131, jan./abr. 2004. Disponível em: <http://www.ibict.br/cionline/viewarticle.php?id=69>. Acesso em: 07 mar. 2007.

OLIVEIRA, E. F. T.; GRÁCIO, M. C. C. Análise a respeito do tamanho de amostras aleatórias simples: uma aplicação na área de Ciência da Informação. DataGramaZero: Revista de Ciência da Informação, v. 6, n. 3, jun. 2005. Disponível em: $<$ http://www.ibict.br/cionline/viewarticle.php?id=69>. Acesso em: 07 mar. 2007.

RUSSO, M. A Biblioteca Universitária no cenário brasileiro. 2007. Disponível em: 
$<$ http://www.cfb.org.br/html/sala_leitura/saladeleitura_12.asp $>$. Acesso em: 27 ago. 2007.

SMITH, L. C. Citation analysis. Library Trends, Illinois, v. 30, n. 1, p. 83-106, Summer 1981.

SPINAK, E. Indicadores cienciométricos. Ciência da Informação, Brasília, DF, v. 27, n. 2, p. 141-148, maio/ago. 1998. Disponível em: $<$ http://www.scielo.br/pdf/ci/v27n2/spinak.pdf $>$. Acesso em: 07 jun. 2006.

STREHL, L.; CASTANHO, V. Bibliograd: metodologia de avaliação para o acervo de graduação. 2007. Disponível em: $<$ http://www.biblioteca.ufrgs.br/modulo8-3.ppt>. Acesso em: 07 out. 2008.

SYLVIA, M. Citation analysis as an unobtrusive method for journal collection evaluation using psychology student research bibliographies. Collection Building: studies in the development and effective use of library resources, New York, v. 17, n. 1, p. 20-28, Mar. 1998. Disponível em: $<$ http://www.emeraldinsight.com/Insight/viewPDF.jsp?Filename =html/Ou tput/Published/EmeraldFullTextArticle/Pdf/1710170103.pdf >. Acesso em: 06 jul. 2006.

TARAPANOFF, K.; MIRANDA, D. M.; ARAÚJO JÚNIOR, R. H. (Colabs.). Técnicas para tomada de decisão nos sistemas de informação. Brasília, DF: Thesaurus, 2004.

TARAPANOFF, K. (Org.). Inteligência organizacional e competitiva. Brasília, DF: Editora da UnB, 2001.

TUÑÓN, J.; BRYDGES, B. Improving the quality of university libraries through citation mining and analysis using two new dissertation bibliometric assessment tools. In: WORD LIBRARY AND INFORMATION CONGRESS. IFLA GENERAL CONFERENCE AND COUNCIL, 71., 2005, Oslo. Libraries: a voyage of discovery. Disponível em: <http://www.ifla.org.sg/IV/ifla71/papers/078e-Tunon Brydges.pdf>. Acesso em: 07 jun. 2006.

URBANO SALIDO, C. El análisis de citas en trabajos de investigadores como método para el estudio del uso de información en bibliotecas. Anales de Documentación, Murcia, v. 4, p. 243-266, 2001. Disponível em: $<$ http://www.um.es/fccd/anales/ad04/ad0400.html>. Acesso em: 17 jun. 2006.

URBANO SALIDO, C. Tipología documental citada en tesis doctorales de informática: bases empíricas para la gestión equilibrada de colecciones. Biblioteconomia i Documentación, Barcelona, n. 5, Dec. 2000. Disponível em: <http://www.ub.es/bid/05urban2.htm>. Acesso em: 17 jun. 2006.

VALLMITJANA, N.; SABATÉ, L.G. Citation analysis of Ph.D. dissertation references as a tool for collection management in an academic chemistry library. College and Research Libraries, v. 69, n. 1, January 2008. 
Disponível em:

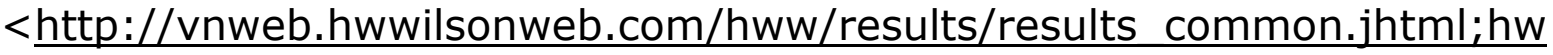
wilsonid=FNAHBOCWYV4DLQA3DILCFGGADUNGIIV0>. Acesso em: 25 ago. 2008.

VERGER, J. Homens e saber na Idade Média. Bauru: Edusc, 1999.

VERGUEIRO, W. C. S. O futuro das bibliotecas e o desenvolvimento de coleções: perspectivas de atuação para uma realidade em efervescência. Perspectivas em Ciência da Informação, Belo Horizonte, v. 2, n. 1, p. 93107, jan./jun.1997.

Desenvolvimento de coleções: uma nova visão para o planejamento de recursos informacionais. Ciência da Informação, Brasília, DF, v. 22, n. 1, p. 13-21, jan./abr. 1993.

. Desenvolvimento de coleções. São Paulo: Polis, 1989.

VIEIRA, S. Princípios de estatística. São Paulo: Pioneira, 2003.

WEITZEL, S. R. Elaboração de uma política de desenvolvimento de coleções em bibliotecas universitárias. Rio de Janeiro: Interciência, 2006.

WEITZEL, S. R. O desenvolvimento de coleções e a organização do conhecimento: suas origens e desafios. Perspectivas em Ciência a Informação, Belo Horizonte, v. 7, n. 1, p. 61-67, jan./jun. 2002.

WILLIAMS, V. K.; FLETCHER, C. L. Materials used by master's students in engineering and implications for collection development: a citation analysis. Issues in Science and Technology Librarianship, Chicago, n. 45, winter 2006, Disponível em: <http://www.istl.org/06winter/refereed1.htm>. Acesso em: 07 jun. 2006. 